\title{
Embedding Concepts of Sex and Gender Health Differences into Medical Curricula
}

\author{
Virginia M. Miller, PhD, Morrisa Rice, MHA, ${ }^{2}$ Londa Schiebinger, $\mathrm{PhD},{ }^{3}$ \\ Marjorie R. Jenkins, MD, ${ }^{4}$ Janice Werbinski, MD, ${ }^{5}$ Ana Núñez, MD, ${ }^{6}$ \\ Susan Wood, PhD, ${ }^{7}$ Thomas R. Viggiano, MD, ${ }^{8}$ and Lynne T. Shuster, MD ${ }^{9}$
}

\begin{abstract}
Sex, a biological variable, and gender, a cultural variable, define the individual and affect all aspects of disease prevention, development, diagnosis, progression, and treatment. Sex and gender are essential elements of individualized medicine. However, medical education rarely considers such topics beyond the physiology of reproduction. To reduce health care disparities and to provide optimal, cost-effective medical care for individuals, concepts of sex and gender health need to become embedded into education and training of health professionals. In September 2012, Mayo Clinic hosted a 2-day workshop bringing together leading experts from 13 U.S. schools of medicine and schools of public health, Health Resources and Services Administration Office of Women's Health (HRSA OWH), the National Institutes of Health (NIH) Office of Research on Women's Health $(\mathrm{ORWH})$, and the Canadian Institute of Health and Gender. The purpose of this workshop was to articulate the need to integrate sex- and gender-based content into medical education and training, to identify gaps in current medical curricula, to consider strategies to embed concepts of sex and gender health into health professional curricula, and to identify existing resources to facilitate and implement change. This report summarizes these proceedings, recommendations, and action items from the workshop.
\end{abstract}

\section{Introduction}

$\mathbf{I}^{\mathrm{N}}$ N THE United States, scientific attention to the array of sex and gender differences impacting medicine resulted, in part, from the feminist movement of the 1960s and 1970s. Women were demanding an integrated approach to their health care and information upon which they could make decisions about treatment options. In 1985, the National Institutes of Health (NIH) Public Task Force on Women's Health concluded that, apart from reproductive issues, little was known about the unique needs of the female patient. ${ }^{1}$ As a result of this report, the NIH Office of Research on Women's Health (ORWH) was created in 1990 to promote and support research on women's health. In that same year, the General Accounting Office (GAO) released a review of $50 \mathrm{NIH}$ pro- posals and found that $50 \%$ included only men, 30\% included both sexes and $20 \%$ did not designate gender. ${ }^{2}$ Soon after, Congress permanently established ORWH with the $1993 \mathrm{NIH}$ Revitalization Act, which mandated that, if relevant, women and minorities be included in clinical research trials; that investigators design clinical trials to ensure that valid scientific analysis could be performed to determine whether differences existed between women and minorities in relation to other study subjects; and that Phase III clinical trials include both sexes in adequate numbers to ensure data could be analyzed for an effect of gender.

These events led to a repository of medical evidence identifying sex- and gender-specific differences in disease incidence, symptomatology, morbidity, and mortality. However, it was not until 2001 when the Institute of Medicine (IOM)

\footnotetext{
${ }^{1}$ Departments of Surgery and Physiology and Biomedical Engineering, Mayo Clinic, Rochester, Minnesota.

${ }^{2}$ Office of Women's Health, Health Resources and Service Administration, Rockville, Maryland.

${ }^{3} \mathrm{EU} / \mathrm{US}$ Gendered Innovations in Science, Health \& Medicine, and Engineering Project, Stanford University, Stanford, California.

${ }^{4}$ Laura W. Bush Institute for Women's Health, Texas Tech University Health Sciences Center, Amarillo, Texas.

${ }^{5}$ Michigan State University College of Human Medicine, Portage, Michigan.

${ }^{6}$ Women's Health Education Program, National Center of Excellence of Women's Health, Drexel University College of Medicine, Philadelphia, Pennsylvania.

7Jacobs Institute of Women's Health, The George Washington University School of Public Health and Health Services, Washington, DC.

${ }^{8}$ Mayo Medical School, Mayo Clinic, Rochester, Minnesota.

${ }^{9}$ Office of Women's Health, Women's Health Clinic Division of General Internal Medicine, Mayo Clinic, Rochester, Minnesota.
} 
asked the question "Does Sex Matter?" that sex and gender were considered as two variables forming the basis of individualized medicine. That report stated "Sex, that is being male or female, is an important basic human variable that should be considered when designing and analyzing studies in all areas and at all levels of biomedical and health related research" which includes investigations of single cells to organisms and from conception to death, "womb to tomb". ${ }^{3}$

Researchers, educators, and health care providers struggle with how to best incorporate information generated from the growing discipline of sex- and gender-based medicine into educational and training programs that will ultimately impact patient care. Curricular models and instructional strategies vary (Table 1). Perhaps most typical, coverage of sex and gender differences, is presented in specific courses such as physiology and pharmacology without application into clinical rotations. ${ }^{4}$ Based on the growing emphasis on individualized medicine, the body of information regarding sex and gender differences in disease, and apparent barriers to incorporating such topics into health professional education, Mayo Clinic hosted a workshop in September 2012 to bring together leaders from health professional training programs. Representatives from 13 U.S. schools of medicine and schools of public health, the NIH ORWH, Health Resources and Services Administration Office of Women's Health (HRSA $\mathrm{OWH}$ ), and the Canadian Institute of Health and Gender (Appendix 1) came together to address the need to integrate sex and gender concepts into medical education and training, to identify gaps in current medical curricula, to propose core competencies, and to share practical strategies for success.

\section{Interprofessional Collaborations in Women's Health Curricula Development}

Although the title of the workshop focused on medical education, it became apparent that topics of sex and gender need to be included in all levels of health care professional education and training. Keynote speaker, Commander (CDR) Morrisa Rice, HRSA OWH, discussed the findings of a HRSAfunded project to identify and provide recommendations re-

Table 1. Sex and Gender Curricular Interventions AND Instructional Strategies

\section{Degree of impact Low (one to several) \\ Medium (one to many) High}

II. Types of strategies
Elective courses or seminars Required: stand-alone didactics

Required: core curricula with longitudinal integration or integrated themes

Didactic: organ/system/symptom based

Problem-based learning

Standardized patients

Self-directed learning and scholars tracks

Online modalities

Clinical education

Interprofessional education

Community-based education

Continuing medical education/faculty development lated to developing competencies in sex and gender not only in medicine but also in baccalaureate nursing, dental, pharmacy, and public health educational training.

An expert panel was consulted to develop process-oriented recommendations including coordinating educational efforts along the continuum of curriculum development to clinical experience, interdisciplinary simulation, and theoretical approaches. Common content areas to foster interprofessional collaborations when addressing sex and gender differences should meet general training needs of professional education including physician-patient communications, biological considerations, selected conditions, behavioral health, and wellness and prevention (Fig. 1). These categories are dynamic, change across the lifespan of the patient, and are influenced by both biological (sex) and sociological (gender) components. To implement and sustain change in existing curricula, CDR Rice emphasized that key stakeholders (i.e., educators, administrators, professional societies) need to be engaged early in the process, a theme that was repeated and emphasized by other speakers throughout the workshop.

Interactions of educators with governmental agencies can be challenging. However, the HRSA Interprofessional Collaboration related to Women's Health Curricula project has fostered several collaborations between federal and nonfederal stakeholders. Another suggestion was for educators to connect with the former Centers of Excellence in Women's Health. Dr. Janine Clayton, Director of the NIH ORWH suggested that leveraging participation with multiple interdisciplinary stakeholders is a more realistic approach. For example, conferences such as this workshop and using various technologies to share curricula and resources will be critical in a financially constrained environment. Gathering evidence on the added value of including training of sex and gender medicine as a routine part of health professional education will be critical to initiate and sustain change. Furthermore, interprofessional collaborations are necessary to identifying currently available resources, as well as to developing new resources. Keeping those resources updated will require continuous effort and financial support.

\section{Designing Sex and Gender Analysis into Research and Teaching}

A barrier to developing sex- and gender-based material for health professional education sometimes reflects confusion or misunderstanding regarding the use of the terms sex and gender. The terms are distinct-not synonymous. According to the IOM report, sex is a narrowly defined term defining living things as male and female based on the complement of sex chromosomes and the presence of reproductive organs. ${ }^{5}$ Gender refers to a complex psychosocial construct that takes into account biology but also the influences of society and environment. ${ }^{5-7}$ Consensus of the workshop attendees was to adopt these definitions (Fig. 2).

Reviews of the literature from 2009 to 2011 found that sex of the experimental material is missing from between $40 \%$ and $80 \%$ of basic science studies using animals or isolated cells and that data from human studies and clinical trials is often not reported by sex even in high impact journals. ${ }^{8-10}$ It is erroneous to assume that specific pathways or mechanisms identified from experiments using material from one sex automatically applies to the other without corroborating 


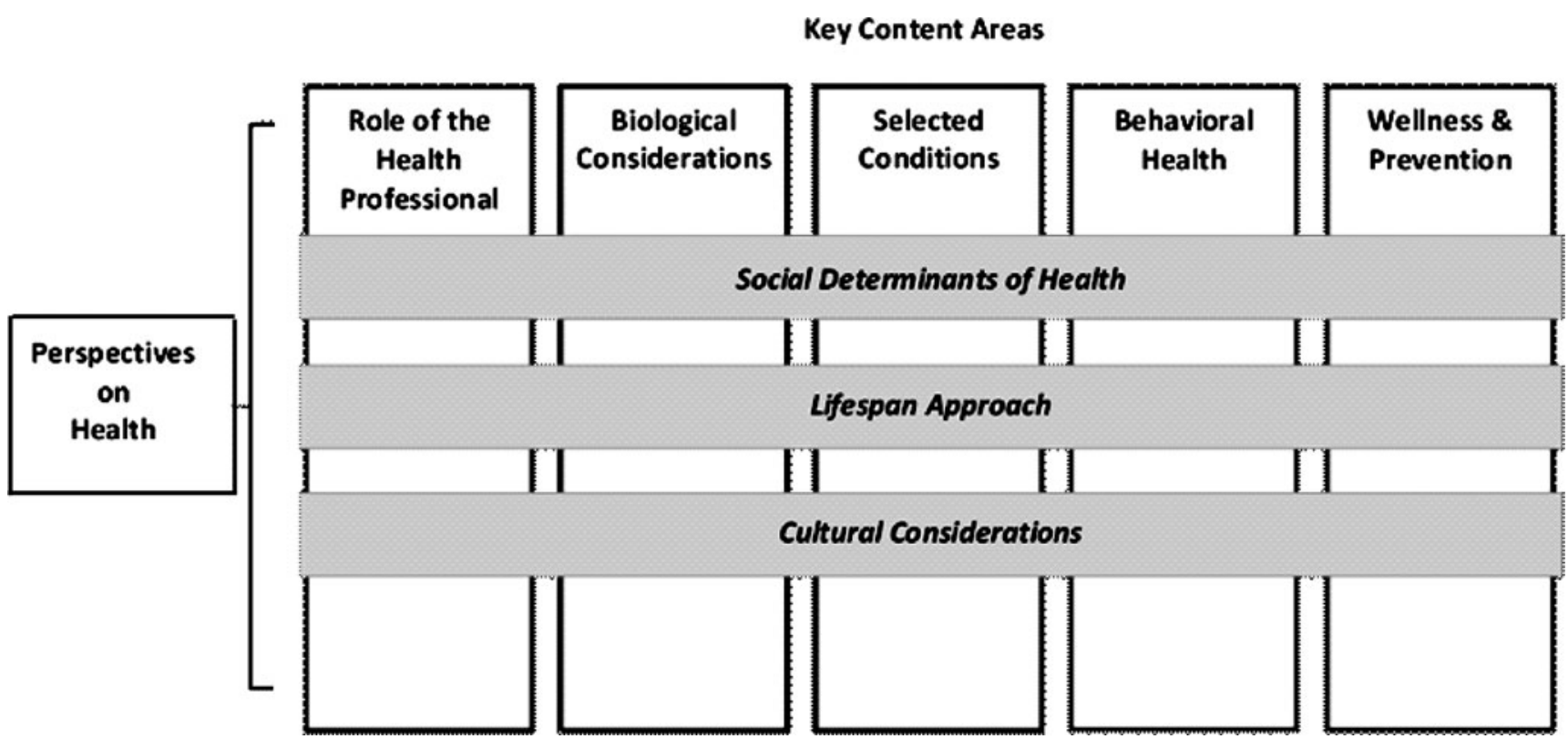

FIG. 1. Key components of an interprofessional curricula. Source: Health Resources and Services Administration Office of Women's Health.

evidence for or against such assumptions. ${ }^{11}$ In addition, the behavior of cells and tissues in isolation may be influenced by the hormonal status, cultural, or environmental influences to which the donor was exposed. The majority of male and female animal (nonhuman) studies are studies of sex differences. The exception being those studies designed specifically to evaluate interactions among environmental factors or social groups. Alternatively, data generated from studies of humans may require analysis by both sex and gender. Therefore, attendees also endorsed the editorial policies of several major scientific journals requiring the reporting of sex of the experimental material. ${ }^{12-15}$

Dr. Londa Schiebinger emphasized how constructs of sex and gender influence all aspects of innovation in science, mathematics, and engineering as well as medicine. Through her efforts as Director of a joint program of Stanford University Center for Gendered Innovation, the European Union Research and Innovation, and the National Science Foundation, a website (www.genderedinnovations.eu) was developed to provide scientists and health care professionals easy access to definitions, methodologies, and examples of how viewing their work through a "gender lens" facilitates innovations. She emphasized that policies, in this case directives from the European Union Research programs, were necessary to direct the change in study design and data analysis. In addition, an effective business model exists for considering sex and gender in technology development. For example,

Sex: being male or female - is genetically determined.

Gender: the identification of being a woman or man,

girl or boy - reflects societal and behavioral factors.

FIG. 2. Definitions of sex and gender adapted from the IOM report. ${ }^{3}$ many medications have been withdrawn from the market due to adverse side effects in women compared with men, and safety devices might be less than adequate because they were modeled and tested only for one sex. The Gendered Innovations website provides lists of resources and editorial policies of scientific and medical journals requiring the reporting of the sex and/or gender of the experimental material, a requirement for scientific rigor. Sex and gender analyses do not exist in a vacuum but serve as resources for innovation. Patient-centered approaches need information from the intersection of sex and gender with other constructs that affect outcomes such as socio-economic class, ethnicity, culture, and physiognomy related to size.

\section{Evaluating the Curriculum}

A challenge is to identify specific areas in which sex and gender content are missing from medical curricula and how to fill these voids. ${ }^{16,17}$ Dr. Marjorie Jenkins, Professor of Medicine and Chief Scientific Officer of the Laura W. Bush Institute for Women's Health at Texas Tech University Health Sciences Center (TTUHSC), presented unpublished data (data available through TTUHSC) from a National Climate Survey administered to the American Association of Medical Colleges New Horizons Group that included the majority of medical schools in the United States and Canada. Of 159 schools surveyed, 44 responded, $70 \%$ of which indicated that they did not have a formal sex- and gender-specific integrated medical curriculum. Asked whether there was adequate coverage of topics where sex- and gender-based evidence exists, $45 \%-70 \%$ ranked their coverage as minimal. Based on these findings TTUHSC initiated a sex and gender integration curricular project, which is now in its third phase. The first phase of the project included dialogue with leadership and identification of educational resources and sources of potential funding. Student Scholar Auditors performed a real-time audit of the existing curricula in years 1 and 2 of their programs to 
specifically identify sex and gender content. Members of a core curriculum committee were identified and included interprofessional leadership and students. In the second phase, the audit findings were cross-referenced with Marianne Legato's Textbook of Gender Specific Medicine (2nd ed., Elsevier, 2011), and a qualitative analysis of curriculum audit enabled a curriculum outline to be developed targeting educational materials needed for formal presentation to the Educational Policy Committee (or other internal curriculum governing bodies). In the third phase, student knowledge and awareness are being assessed through an adapted survey instrument prior to beginning the new curriculum. For internal and external communication, SharePoint and curriculum websites are utilized. Evaluations are ongoing to identify areas in need of further integration and to identify processes for sustaining these changes. This model lent itself to interprofessional development as the TTUHSC Schools of Nursing and Pharmacy are now proceeding with Phase 1 student audits.

Key to the success of incorporating sex and gender content into medical education and training is the need to evaluate whether the organization is ready to embrace change and the need to provide ongoing education of administrators, faculty and students through seminars, guest speakers, continuing medical education (CME) courses, workshops and other available teaching venues. Caution needs to be exercised in discussion with leadership who might equate sex and gender curricula with sex education and women's health as encompassed by obstetrics and gynecology, limited to reproductive medicine.

\section{Disseminating Proven Reforms}

Dissemination of proven techniques and reform are essential to bringing cultural change to health care professional education so that individual institutions and programs do not reinvent processes and duplicate existing materials. Business models encourage innovative thinking, which can be applied to curricular change, but it is important to implement the innovation, emphasized Dr. Ana Núñez, Director of the Women's Health Education Program and Office of Urban Health and Equity Research at Drexel University College of Medicine. Drexel, in collaboration with other universities, developed a curricular model with the patient at the center. It was based on concepts of sex and gender medicine, although at the time this specific terminology was not used. The model includes a discrete unit that serves as a clearinghouse of information as well as longitudinally integrated and elective components. Integration occurs across Drexel's two tracks: problem-based cases and a symptom-based module. A successful approach was to identify the goal (e.g., to reduce health disparities) and then to work to develop the means to achieve that goal. This approach may be difficult to apply to curriculum design often constrained by maintaining the status quo.

Engaging external funders and advisors may facilitate the process by providing a source for innovation and oversight as happened with the research funding application process for the European Union program supporting sex and gender medical research. Likewise, internal seminar series and students as curricular catalysts can drive change in the curriculum. If the topics are relevant and challenging, students will be engaged.

Although technology can be leveraged to disseminate information, it does not replace personal interactions such as panels to engage students and faculty in building communitybased research and experiences. Within these personal interactions, cognitive frameworks enable participants to focus and identify what might be the same as well as what might be different. In other words, it is important to know the difference between the phrases "there are no data about differences" and "the data show that there are no differences." These statements are critical in order to avoid assumptions that would bias interpretation and application of research data by overgeneralization.

As was stated by Dr. Schiebinger, there is a business case for attending to sex and gender differences because it raises the standard of care for everyone. Dr. Joy Johnson, Scientific Director of the Institute of Gender and Health for Canadian Institutes of Health Research commented on how key ideas to explore variance in gender difference could push innovation in medial curricula. A place to start is critical evaluation of the literature in terms of what are the characteristics of the study population upon which conclusions are being drawn and to whom results of the study would be applied. For example, reports of a new drug to be prescribed to many ethnicities and women were tested only in a population of Scandinavian men. These types of discussions with students and health care providers will drive change in research and curricula.

\section{Translating Sex and Gender Care to the Community}

A natural extension of renovating health professional education is the translation of new information to CME or provider education which impacts the community. Dr. Susan Wood, Director of the Jacobs Institute of Women's Health at the George Washington University School of Public Health and Health Services, used the Heart Truth ${ }^{\circledR}$ Campaign, a women's health campaign about sex and gender differences, as an example of how to educate providers and patients for better results in prevention, diagnosis, management, and treatment of heart disease relative to the sex of the patient. CME Medscape programs from George Washington University provide resources for health care providers with both evidence-based and effectiveness-based guidelines. As for undergraduate medical curricula, developing CME curricula must be relevant for medical practitioners with different levels of training or scope of practice. Asking the simple question "why should I care?" can be used to develop the most patient-centered approaches which will be highly relevant to clinicians.

\section{Development of Digital Resources and Teaching Tools}

Various types of materials have been developed for specific aspects of sex- and gender-based curricula (Appendix 2). However, educators may not know where to look and may devote resources to developing new materials that may or may not be an improvement on existing materials. Dr. Janice Werbinski has authored curricula for a Women's Health Track in Michigan State University's Internal Medicine Residency Program. She also serves as chair of the Women's Health Working Group of the American Medical Women's Association, through which she was instrumental in establishing the "Sex and Gender Women's Health Collaborative" at www.sgwhc.org.

The project goal is to assemble women's health and sex and gender curricular materials into a universally accessible digital resource for diverse training programs and clinical practices. To 
achieve this goal, there are points of engagement that need to be touched both internally and externally to the institution/organization (Fig. 3). Consensus supported the need for a centralized repository for sex and gender materials and identified limitless benefits of a shared site regarding the type of materials that could be shared (e.g., webinars, references, webcasts, journal club reviews). In an ideal world, sex- and gender-specific health programs would have budget and staff in every medical school and educational setting so that research training and clinical care would include sex- and gender-specific applications as standard. Also, board-certifying exams would include sex- and gender-based evidence as "best practices." However, proprietary issues often prevent all stakeholders from working together.

Initial funding for the Sex and Gender Women's Health Collaborative came from American Medical Women's Association and American College of Women's Health Physicians. The future challenge is to find mechanisms and funds to sustain the site through outreach to various professional

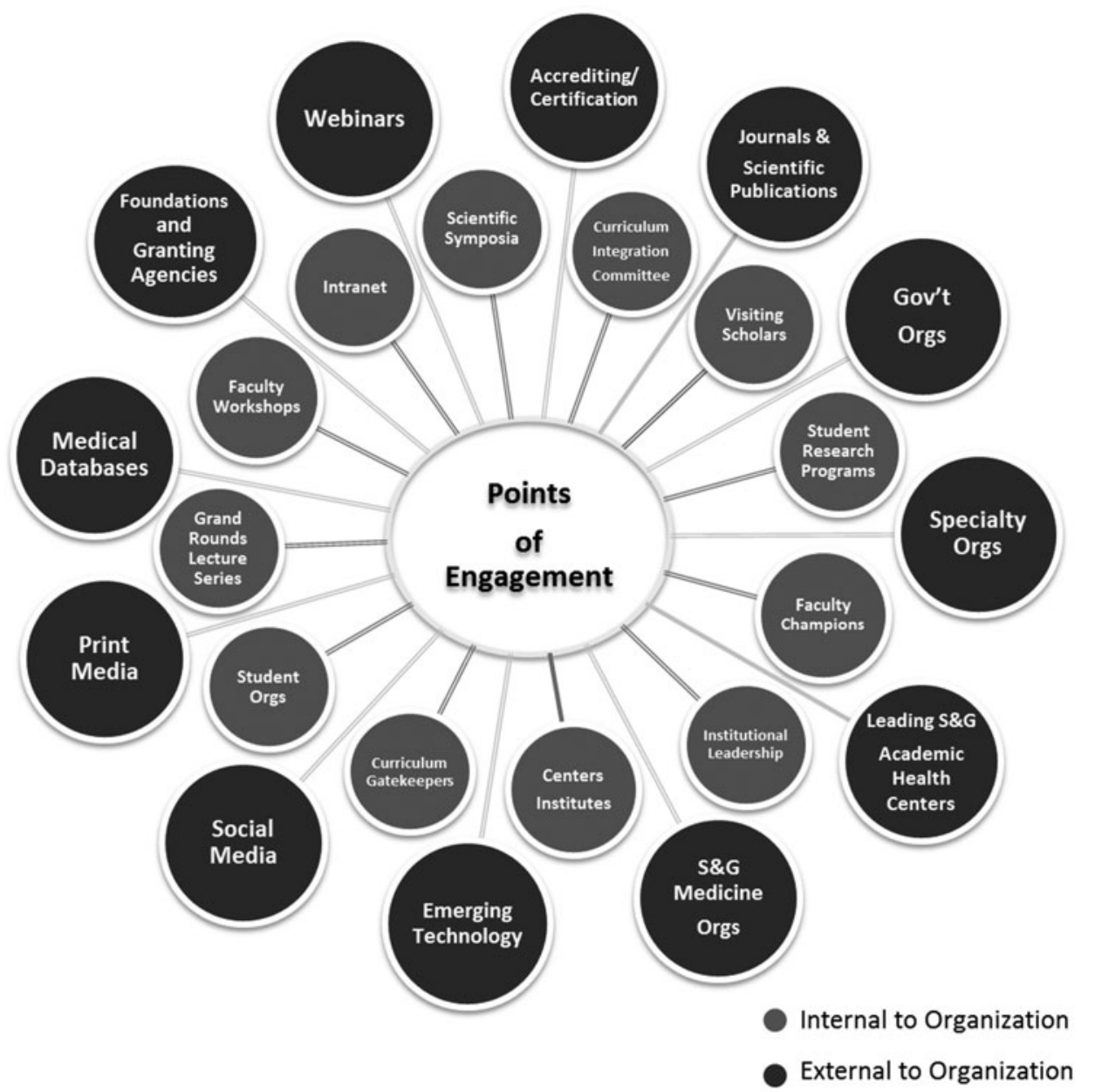

Source: () 2012 TTUHSC Laura W. Bush Institute for Women's Health

FIG. 3. Schematic of stakeholders internal and external to an organization and tools to be engaged in implementing sex and gender concepts into medial education. Examples of Accrediting and Certification Bodies: Liaison committee on Medical Education (LCME), Accreditation Council for Graduate Medical Education (ACGME), American College of Obstetrics and Gynecology (ACOG); Curriculum Gatekeepers: Deans of Curriculum, Block Leaders, Educational Policy Committee, Curriculum Integration Committee, Core Faculty Group Leading the Curriculum Integration; Emerging Technologies: Smart Phone and Tablet Apps; Faculty Champions: Grass-roots engagement of Basic and Clinical Faculty to Pioneer Efforts and Engage Others; Institutional Leadership: President, Deans, Assoc/Asst Deans, Chairs; Sex and Gender (SG) Medicine-Focused Organizations E Initiatives: Society for Women's Health Research, Sex and Gender Women's Health Collaborative, Organization for the Study of Sex Differences, International Society of Gender Medicine, North American Menopause Society; Government Organizations: Department of Health and Human Services Office for Women's Health, National Institutes of Health Office for Research on Women's Health, Federal Drug Administration, Health Resource Service Administration; Medical Database/Search Engines: Pub Med, Ovid, Up-to-Date, Medscape, MD Consult; Journals E Other Scientific Publications: Gender Medicine, Journal of Women's Health, Institute of Medicine Reports; Print Media: Monographs, Reviews, Commentaries; Specialty Organizations: American Academy of Family Medicine (AAFM), American Board of Internal Medicine (ABIM), American College of Physicians (ACP), American Congress of Obstetrics and Gynecology (ACOG), Association of Professors in Gynecology and Obstetrics (APGO), American Medical Student Association (AMSA), Association of American Medical Colleges AAMC); Social Media: Blogs, Twitter, Facebook, LinkedIn Webinars \& Online C. 
societies and to develop collaborations with schools of medicine, NIH, HRS, and the Federal Drug Administration. All educators interested in sex and gender medicine are encouraged to provide material to the web site and to be proactive by asking questions regarding inclusion of both sexes and demanding analysis of results by sex in articles that they might review.

The initial focus of the "Sex and Gender Women's Health Collaborative" was at the level of medical school education in order to have the most substantial immediate impact. However, the long-term goal was always to provide a resource that can be used by researchers, clinical faculty, and CME programs. The desire is to include other audiences leading to a "health care professional collaborative" that would allow other contributors to bring their expertise (e.g., in research or policy) and to include the initiatives in the international community as well. Professional societies such as the Organization for the Study of Sex Differences, Endocrine Society, and the American Physiological Society through editorial policies, meetings, and symposia could provide the basic science for such a site.

Success of this project requires networking and one exciting ancillary project that developed from the initial collaborations was the National Board of Medical Examination (NBME) project. This project involved a group of 30 scholars, educators, and researchers in sex and gender medicine to review all three of the NBME exams given to medical students in the United States to identify any gaps in knowledge in the area of sex and gender medicine. The group was given the opportunity to propose content and suggest revisions to existing materials to fill identified gaps in sex and gender medicine.

\section{Leading Cultural Change}

The challenge of navigating sustainable change is to integrate and enrich existing curricula not simply additional material. Dr. Thomas Viggiano, Associate Dean for Faculty Affairs at Mayo Medical School, focused on the business model to create a "cultural change that sticks." ${ }^{18}$ He emphasized that policy or imperatives for change must drive the curricula. Passionate advocates are often skilled in leveraging minimal resources, but may need expanded resources to enact change. A continuum is needed from undergraduate medical education to continuous professional development and interprofessional education. The obvious question becomes, if we work in teams, why not learn in teams? Cultural change must occur not only within a given institution but also across institutions of academic medicine and extend to the practitioner workforce in order to positively influence patient outcomes.

A useful model to implement lasting change in medical education comes from business leaders. ${ }^{18}$ An effective strategy to implement change is to align the change within the culture of the institution. Because sex and gender are health determinants, incorporating sex and gender content into medical curricula is aligned with missions to provide equitable care through patient-centered and evidence-based practice. When strengths of the existing culture are honored, change will be seen as desired and positive. To achieve the greatest impact, prioritization of attitudes, behaviors, competencies, and practices is required to identify those mechanisms or knowledge components most rapidly translatable into practice and policy. Developing learning resources that can be quickly adopted by already overburdened faculty and administrators (e.g., ready-to-use cases) will provide for efficient integration into educational programs. Change ultimately needs to be integrated both formally through oversight of decision-making practices and reporting with clear policies and metrics but also informally through networking and conversations within communities of interest. While the formal mechanisms provide the rationale of why we are doing this, informal mechanisms engage our hearts so that the change becomes the self-interest of educators and providers. Finally, monitor change through performance indicators (e.g., scores on NBME tests, graduation questionnaires, accreditation standards, maintenance of certification, and ultimately patient outcomes). Core behaviors or competencies need to be developed not only for professionals but also for the public. The reality is that change is forthcoming in health care practices and these changes demand the business case for curricular change. Embedding sex and gender concepts into medical curricula will be important to assure high quality individualized health care for the future.

\section{Consensus}

It is critical to present sex and gender as topics that impact all areas of health and health care. Successful curricular change requires (1) assessing the readiness of your organization to think about change; (2) emphasizing the business case for change and showing alignment to the mission of your organization; (3) engaging students; and (4) providing leaders and faculty with easy-to-use, well-designed prepared teaching material that can be incorporated into existing curricula.

Table 2. Practical Steps and Milestones as a Guide to Implement Change in Medical Curricula

Years 1

1. Develop an "elevator speech," that is, a one- to two-sentence stating goal and rationale

2. Internal education: ensure that leaders, faculty, staff, and students understand the definitions and difference of "sex" and "gender"

3. Garner support of leadership

4. Internal audit of existing curriculum to assess gaps in content

Years 2

1. Identify faculty and student champions

2. Ensure that current and prospective students are aware of the Dean's priority for sex- and gender-based curriculum

3. Identify curriculum committee members and begin discussions, include student representatives

4. Share existing resources with faculty

5. Seek funding (i.e. endowed chair, faculty with sex and gender expertise)

Years $3 \& 4$

1. Add sex and gender items to postgraduate survey

2. Continue curriculum committee work

3. Continue to seek funding

Years 5

1. Complete new curriculum

2. Continue to seek targeted funding

3. Evaluate impact from student course evaluations

4. Evaluate, update and refine goals and objectives 
Curricula must be built on evidence from basic science and clinical studies that investigate sex and gender differences and report results accordingly. Existing curricula need to be evaluated as to whether or not they already incorporate sex and gender medicine. It might be possible to expand upon what already exists (e.g., information related to cardiovascular disease or dementia). Incorporating existing resources and information about sex and gender differences into existing material could catalyze more intensive efforts to gather and develop access to materials that are not yet organized and to identify advisory groups that would review and update content. The highest level of effort would require development of original materials such as case reports on various topics or curriculum concept maps and outcome measures which could move toward global integration with policy groups and the Cochrane reviews as examples.

Stakeholders involved in developing changes for professional health care education are numerous and include students, faculty, deans, alumni, donors, and advocates (Fig. 3). Meetings with students, faculty champions, and donors can help clarify the vision and language. The development of a mission and vision statement, goals, and measurable objectives can be discussed with curricular planning committees, department chairs, and deans for consideration and buy-in. Practical steps and milestones (suggested in Table 2) can be applied to parallel plans for marketing and fundraising.

While initial engagement of accreditation and licensing organizations has been essential to provide the impetus for change, continued efforts are required to make the changes sustainable and evaluation of patient outcomes will be important to assess the ultimate value or impact of the efforts. Shifts in curricula and organization culture take time but $\mathrm{cu}-$ mulative small steps will provide lasting change.

\section{Acknowledgments}

The workshop was made possible by funding from the Mildred L. and Garnet L. Findling Named Visiting Professorship in the Mayo Medical School, the Mayo Clinic Office of Women's Health and the Mayo Clinic Specialized Center for Research on Sex Differences, NIH AG44170. The viewpoints in this article are those of the authors and do not necessarily represent the official positions of the U.S. Department of Health and Human Services, or the Health Resources and Services Administration.

\section{Author Disclosure Statement}

None of the authors have financial conflicts of interest to report.

\section{References}

1. Women's Health. Report of the Public Health Service Task Force on Women's Health Issues. Public Health Rep 1985; 100:73-106.
2. Nadel MV. National Institutes of Health: Problems in Implementing Policy on Women in Study Populations. Washington, DC: General Accounting Office, 1990.

3. Wizemann TM, Pardue ML. Exploring the Biological Contributions to Human Health: Does Sex Matter? Board on Health Sciences Policy. Washington, DC: Institute of Medicine, 2001, p. 173.

4. Miller VM, Flynn PM, Lindor KD. Evaluating sex and gender competencies in the medical curriculum: a case study. Gend Med 2012;9:180-186.e183.

5. Wizemann TM, Pardue ML, eds. Exploring the Biological Contributions to Human Health: Does Sex Matter? Washington, DC: The National Academies Press, 2001.

6. Legato MJ. Principles of Gender-Specific Medicine. Second edition. London: Academic Press, 2009.

7. Oertelt-Prigione S, Regitz-Zagrosek V. Sex and Gender Aspects in Clinical Medicine. Springer, London, 2012:201.

8. Beery AK, Zucker I. Sex bias in neuroscience and biomedical research. Neurosci Biobehav Rev 2011;35:565-572.

9. Taylor KE, Vallejo-Giraldo C, Schaible NS, Zakeri R, Miller VM. Reporting of sex as a variable in cardiovascular studies using cultured cells. Biol Sex Differ 2011;2:11.

10. Institute of Medicine. Sex-Specific Reporting of Scientific Research: A Workshop Summary. Washington, DC: The National Academies Press, 2012.

11. Cahill L. A half-truth is a whole lie: on the necessity of investigating sex influences on the brain. Endocrinology 2012; 153:2541-2543.

12. Miller VM. In pursuit of scientific excellence: sex matters. Am J Physiol Heart Circ Physiol 2012;302:H1771-1772.

13. Blaustein JD. Animals have a sex, and so should titles and methods sections of articles in Endocrinology. Endocrinology 2012;153:2539-2540.

14. Arnold AP, Lusis AJ. Understanding the sexome: measuring and reporting sex differences in gene systems. Endocrinology. 2012;153:2551-2555.

15. Klein SL. Immune cells have sex and so should journal articles. Endocrinology 2012;153:2544-2550.

16. Henrich JB. Women's health education: a decade of change. Acad Med 2000;75:1048-1049.

17. Henrich JB, Viscoli CM. What do medical schools teach about women's health and gender differences? Acad Med 2006;81:476-482.

18. Katezenback J, Steffen I, Kronley C. Cultural change that sticks. Harvard Business Review 2012;July-August:110-117.

Address correspondence to: Virginia M. Miller, PhD

Departments of Surgery and Physiology and Biomedical Engineering

Medical Sciences Building 4-62 Mayo Clinic

200 First Street SW

Rochester, MN 55905

E-mail: miller.virginia@mayo.edu 


\section{APPENDIX 1: LIST OF FACULTY AND PARTICIPANTS}

Carl F. Anderson, MD

Mayo Clinic

twohorns@chartermi.net

Delia M. Camacho, PhD

School of Health Professions

University of Puerto Rico Medical Sciences

delia.camacho@upr.edu

Janine Austin Clayton, MD

Director, Office of Research for Women's Health

National Institute of Health

claytonja@od.nih.gov

Shivani Dhawan, BS

Cedars-Sinai Heart Institute

Women's Heart Center

dhawans@cshs.org

Richard Dickerson, PhD

Texas Tech University Health Sciences Center

richard.dickerson@ttuhsc.edu

Priscilla M. Flynn, DrPH

School of Dentistry

University of Minnesota

flynn125@umn.edu

Salma Iftikhar, MD

Mayo Clinic

iftikhar.salma@mayo.edu

Marjorie Jenkins, MD

Professor of Medicine, Division of Women's Health and Gender-Specific Medicine

Texas Tech University Health Sciences Center

marjorie.jenkins@ttuhsc.edu

Jani R. Jensen, MD

Mayo Clinic

jensen.jani@mayo.edu

Joy Johnson, PhD, RN, FCAHS

Scientific Director

Institute of Gender and Health

Canadian Institutes of Health Research

University of British Columbia

joy.johnson@ubc.ca

Sabrina A. Matoff-Stepp, PhD

Director, HRSA Office of Women's Health

smatoff-stepp@hrsa.gov

Bradley B. Miller, MD

Texas Tech University Health Sciences Center

bradley.miller@ttuhsc.edu

Virginia M. Miller, PhD

Professor, Surgery and Physiology

Mayo Clinic

Immediate Past President of the Organization for the Study of Sex Differences

miller.virginia@mayo.edu

Ana E. Núñez, MD

Director of the Center of Excellence and Women's Health Education Program
Drexel University College of Medicine

anunez@drexelmed.edu

Cheri L. Olson, MD

Mayo Clinic Health System

olson.cheri@mayo.edu

Limor Raz, PhD

Mayo Clinic

Raz.limor@mayo.edu

CDR Morrisa Rice, MHA

Senior Public Health Analyst

HRSA Office of Women's Health

mrice@hrsa.gov

Jane F. Reckelhoff, PhD

University of Mississippi Medical Center

Women's Health Research Center

jreckelhoff@umc.edu

April E. Ronca, PhD

Wake Forest School of Medicine

aronca@wakehealth.edu

Matthew A. Saracusa

Cedars Sinai Medical Center

saracusam@cshs.org

Londa Schiebinger, PhD

John L. Hinds Professor of History of Science,

Director of the EU/US Gendered Innovations in Science, Health \& Medicine, and Engineering Project

Stanford University

schieb@stanford.edu

Lynne T. Shuster, MD

Director, Office of Women's Health

Consultant, Women's Health Clinic

Mayo Clinic

lshuster@mayo.edu

Thomas R. Viggiano, M.D., M.Ed.

Associate Dean for Faculty Affairs

at Mayo Medical School,

Professor, College of Medicine,

Mayo Clinic

viggiano.thomas@mayo.edu

Janet Vittone, M.D.

Consultant in General Internal Medicine Mayo Clinic

vittone.janet@mayo.edu

Janice Werbinski, MD, FACOG

Michigan State U College of Human Medicine

drwerb@aol.com

Susan F. Wood, PhD

Associate Professor of Health Policy, Director of the Jacobs Institute of Women's Health

George Washington University School of Public Health and Health Services

sfwood@gwu.edu

Kimberly Templeton, MD

University of Kansas

osteocyte@msn.com 


\section{APPENDIX 2: PROFESSIONAL RESOURCES}

\section{Textbooks}

- Legato M. Principles of Gender-Specific Medicine. 2nd ed. Elsevier. 2011.

- Oertelt-Prigione, Regitz-Zagrosek. Clinical Aspects of Gender Specific Medicine. Springer. 2012.

- Schenk-Gustafsson K, DeCola PR, Pfaff SW, Pisetsky DS. Handbook of Clinical Gender Medicine. Karger. 2012.

- Regitz-Zagrosek, V. ed. Sex and Gender Differences in Pharmacology. Springer-Verlag 2012.

\section{Web-based Research and Educational Resources}

- Sex and Gender Women's Health Collaborative.

Available at http://www.sgwhc.org

- Stanford University's Gendered Innovations.

$\bigcirc$ Available at http://genderedinnovations.stanford .edu

- Canadian Institute of Gender Health. What a Difference Sex and Gender Make.

Available at http://www.cihr-irsc.gc.ca/e/44082 .html.

\section{Web-based Continuing Medicine Education Courses}

- NIH ORWH Sex and Gender Differences in Health and Behavior

$\bigcirc$ Available at http://sexandgendercourse.od.nih.gov
- NIH ORWH The Basic Science and the Biological Basis for Sex and Gender Differences

Available at http://sexandgendercourse.od.nih.gov

- TTUHSC Laura W. Bush Institute for Women's Health. Y Does X Make A Difference?

$\bigcirc$ Available at www.laurabushinstitute.org.

- Women's Health Info Site: Sex and Gender Resource for Clinicians and Trainees

$\bigcirc$ Available at http://whepducom.blogspot.com

- National Association of Women's Health Medical Educators Faculty Guide (NAWHME)

- Resource listing of various educational modalities to use in integration efforts

$\bigcirc$ Available at http://www.drexelmed.edu/Home/ OtherPrograms/WomensHealthEducationProgram/Resources.aspx

\section{Professional Membership Organizations}

- Organization for the Study of Sex Differences. Available at http://www.ossdweb.org

- International Society of Gender Medicine. Available at http://www.isogem.com

\section{Journals}

- Biology of Sex Differences. Available at http://www .bsd-journal.com

- Journal of Women's Health. Available at http://www .liebertpub.com 